\title{
Enhancement of autophagy is a potential modality for tumors refractory to radiotherapy
}

\author{
Y Kuwahara ${ }^{1}$, T Oikawa ${ }^{1}$, Y Ochiai ${ }^{1}$, MH Roudkenar ${ }^{2}$, M Fukumoto', ${ }^{1}$ T Shimura ${ }^{1}$, Y Ohtake ${ }^{3}$, Y Ohkubo ${ }^{3}$, S Mori ${ }^{4}$, Uchiyama $^{5}$ \\ and M Fukumoto ${ }^{*, 1}$
}

Radiotherapy is a well-established treatment for cancer. However, the existence of radioresistant cells is one of the major obstacles in radiotherapy. In order to understand the mechanism of cellular radioresistance and develop more effective radiotherapy, we have established clinically relevant radioresistant (CRR) cell lines, which continue to proliferate under daily exposure to 2 Gray (Gy) of X-rays for $>\mathbf{3 0}$ days. X-ray irradiation significantly induced autophagic cells in parental cells, which was exiguous in CRR cells, suggesting that autophagic cell death is involved in cellular radiosensitivity. An autophagy inducer, rapamycin sensitized CRR cells to the level of parental cells and suppressed cell growth. An autophagy inhibitor, 3-methyladenine induced radioresistance of parental cells. Furthermore, inhibition of autophagy by knockdown of Beclin-1 made parental cells radioresistant to acute radiation. These suggest that the suppression of autophagic cell death but not apoptosis is mainly involved in cellular radioresistance. Therefore, the enhancement of autophagy may have a considerable impact on the treatment of radioresistant tumor.

Cell Death and Disease (2011) 2, e177; doi:10.1038/cddis.2011.56; published online 30 June 2011

Subject Category: Cancer

Radiotherapy and radiochemotherapy are well-established treatment modalities for various cancers. Tumor cells have the capacity to cope with radiotherapy and chemotherapy through multiple pathways of growth arrest and cell death. ${ }^{1}$ Various modes of cell death have been known, such as necrosis, apoptosis, accelerated senescence, mitotic catastrophe and autophagic cell death. ${ }^{2-4}$ Among these, apoptosis has been the most extensively studied and has revealed to be the primary mode of cell death in leukemia and lymphoma cells. ${ }^{5}$ However, the concept of cell death is continuously evolving and the role of apoptosis in radiation or anticancer drug treatment is being reappraised. ${ }^{6}$ Although death after irradiation in leukemia and lymphoma is preceded by apoptotic changes, apoptosis has little or even no role in the killing of epithelial neoplastic cells by radiation. ${ }^{7}$ Moreover, early response of cell death, apoptosis is not necessarily correlated with overall tumor sensitivity to anticancer treatment. ${ }^{8,9}$

Compared with other cell death patterns, autophagy induced by radiation or anticancer drugs is less studied. ${ }^{4}$ Dual role of autophagy has been reported, cell death and survival. Therefore, autophagy is considered to be a doubleedged sword in the process of tumor development. ${ }^{10}$ Autophagy suppresses tumor formation by triggering a nonapoptotic cell death program. The Beclin-1 gene, an ortholog of Apg6, which participates in the induction of autophagy in response to starvation is reported to be one of tumorsuppressor genes. ${ }^{11}$ On the contrary, the activation of autophagy may permit cancer cells to survive within the nutrient-poor environment. ${ }^{12}$ Anticancer drug-induced autophagy can lead either to cell death or alternatively to protection against cell death. An anticancer drug, tamoxifen induces autophagic cell death in human mammary carcinoma MCF-7 cells. ${ }^{13}$ By contrast, in response to sulindac and tumor necrosis factor- $\alpha$, autophagy is induced as a cell survival mechanism. ${ }^{14-16}$ Autophagy may protect some cancer cells from ionizing radiation possibly by removing damaged macromolecules and organelles such as mitochondria, which could protect against apoptosis and allow continued survival of transformed cells. ${ }^{17}$ lonizing radiation does not induce apoptosis but induces autophagic changes in glioblastoma cell lines irrespective of their relative radiosensitivity. ${ }^{18}$ It is suggested that a basal enhanced level of autophagy in cancer cells contributes to therapy resistance but prolonged activation of autophagy may lead to cell death by cellular selfdegradation. ${ }^{19}$

In order to develop more effective tumor radiotherapy, we have recently established clinically relevant radioresistant (CRR) cell lines, HepG2-8960-R and HepG2-R from HepG2, and SAS-R from SAS, independently. ${ }^{20,21}$ These cells continue to proliferate with daily exposure to 2 Gray (Gy) of X-rays for $>30$ days, which corresponds to the standard protocol of fractionated radiotherapy for cancer treatment. This study revealed that CRR cells were refractory to the induction of autophagy after irradiation and that facilitation of

\footnotetext{
${ }^{1}$ Department of Pathology, Institute of Development, Aging and Cancer, Tohoku University, Sendai, Japan; ${ }^{2}$ Research Center, Iranian Blood Transfusion Organization, Tehran, Iran; ${ }^{3}$ Department of Radiopharmacology, Tohoku Pharmaceutical University, Sendai, Japan; ${ }^{4}$ Department of Maxillofacial Surgery, Graduate School of Dentistry, Tohoku University, Sendai, Japan and ${ }^{5}$ Department of Cell Biology and Neuroscience, Juntendo University Graduate School of Medicine, Tokyo, Japan ${ }^{*}$ Corresponding author: M Fukumoto, Department of Pathology, Institute of Development, Aging and Cancer, Tohoku University, Sendai 980-8575, Japan. Tel: + 8122717 8507; Fax: + 8122717 8512; E-mail: fukumoto@idac.tohoku.ac.jp Keywords: radioresistant cells; radiotherapy; autophagy; rapamycin; 3-methyladenine Abbreviations: CRR, clinically relevant radioresistant; RPM, rapamycin; HDS, high-density survival; 3-MA, 3-methyladenine; FR, fractionated radiation; Gy, Gray; RPMI, Roswell Park Memorial Institute; PBS, phosphate-buffered saline; RT, room temperature; AR, acute radiation 
a

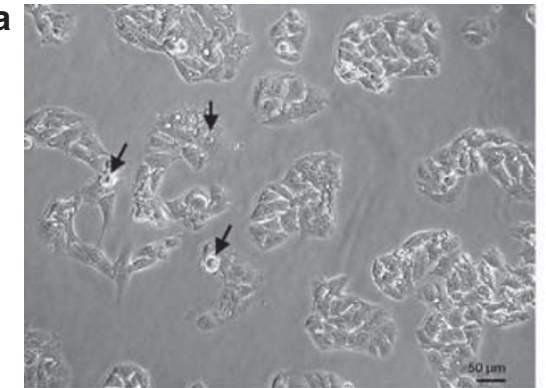

c

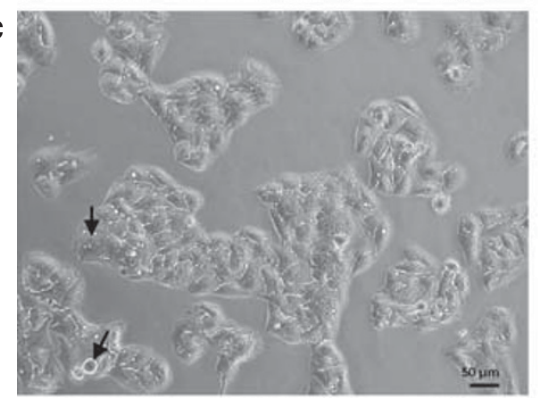

e

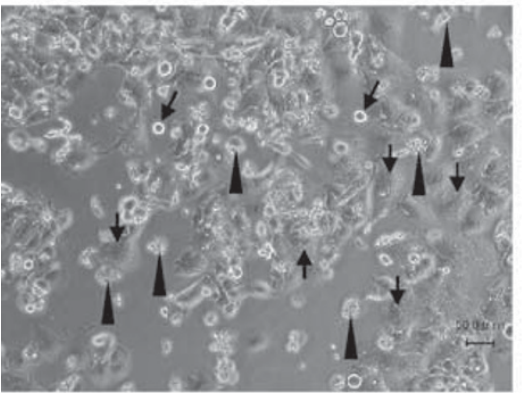

g

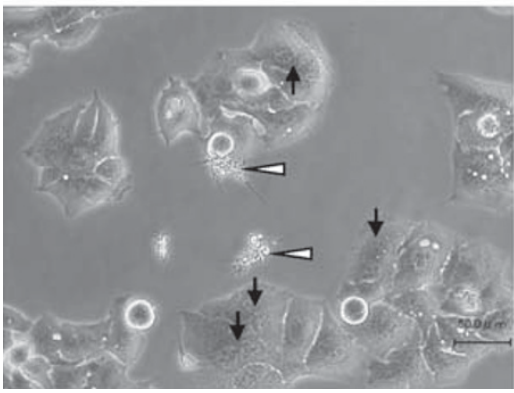

b

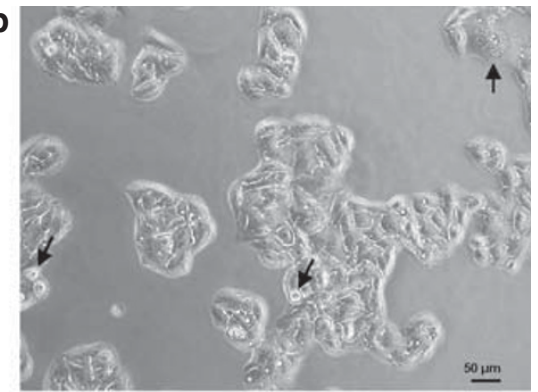

d

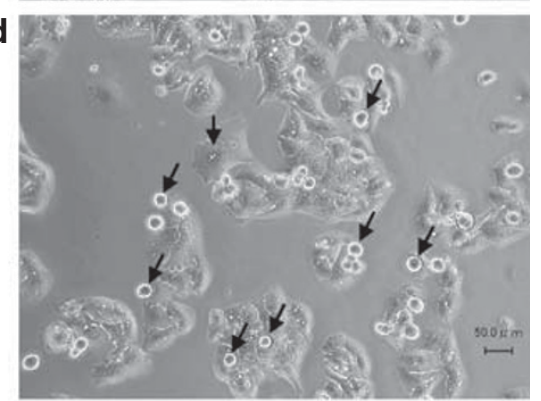

f

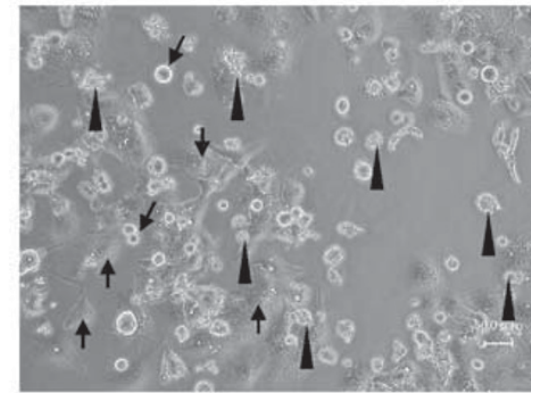

h

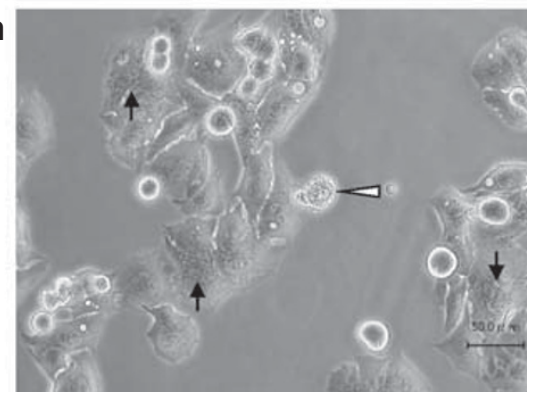

Figure 1 Microscopic appearance of parental HepG2 cells after exposure to a single dose of 10-Gy X-rays. (a) Mitotic figures but a few were observed in HepG2 cells without irradiation. (b) No remarkable changes but the increase in cell size were observed 1 day after exposure. (c) The increase in cell size was obvious 2 days after exposure. (d) Mitotic figures were apparent 3 days after exposure (black arrows). (e) At day 5 after exposure, a frequent number of dying cells were seen (black arrow heads). Multinucleated cells showing mitotic catastrophe were also increased (white arrows). (f) At day 7 after exposure. (g) Dead cells with apoptotic bodies (arrow heads; 5 days after exposure to X-rays). (h) Dead cell without apoptotic bodies (arrow head; 5 days after exposure to X-rays)

autophagy by rapamycin (RPM) abrogated the CRR phenotype. We also found that repression of autophagy induced radioresistance in non-CRR parental cells.

\section{Results}

Microscopic analysis of radiation-induced cell death after acute exposure to $10 \mathrm{~Gy}$ of $\mathrm{X}$-rays. We pursued morphological changes characteristic to radiation-induced cell death. Within 2 days after 10 Gy of acute radiation (AR), prominent changes in morphology were not observed in HepG2 cells other than a slight increase in the cell size (Figures $1 \mathrm{a}-\mathrm{C}$ ). At day 3 after AR, the number of round cells, that is, mitotic cells increased (Figure 1d). Thereafter dead cells became obvious and multinucleated cells, characteristic to mitotic catastrophe, were also observed (Figures 1e and f). Dying cells were classified into two types: apoptotic cells with apoptotic bodies (Figure 1g) and non-apoptotic cells without apoptotic bodies (Figure 1h). The frequency of non-apoptotic cells was significantly higher than that of apoptotic cells. 

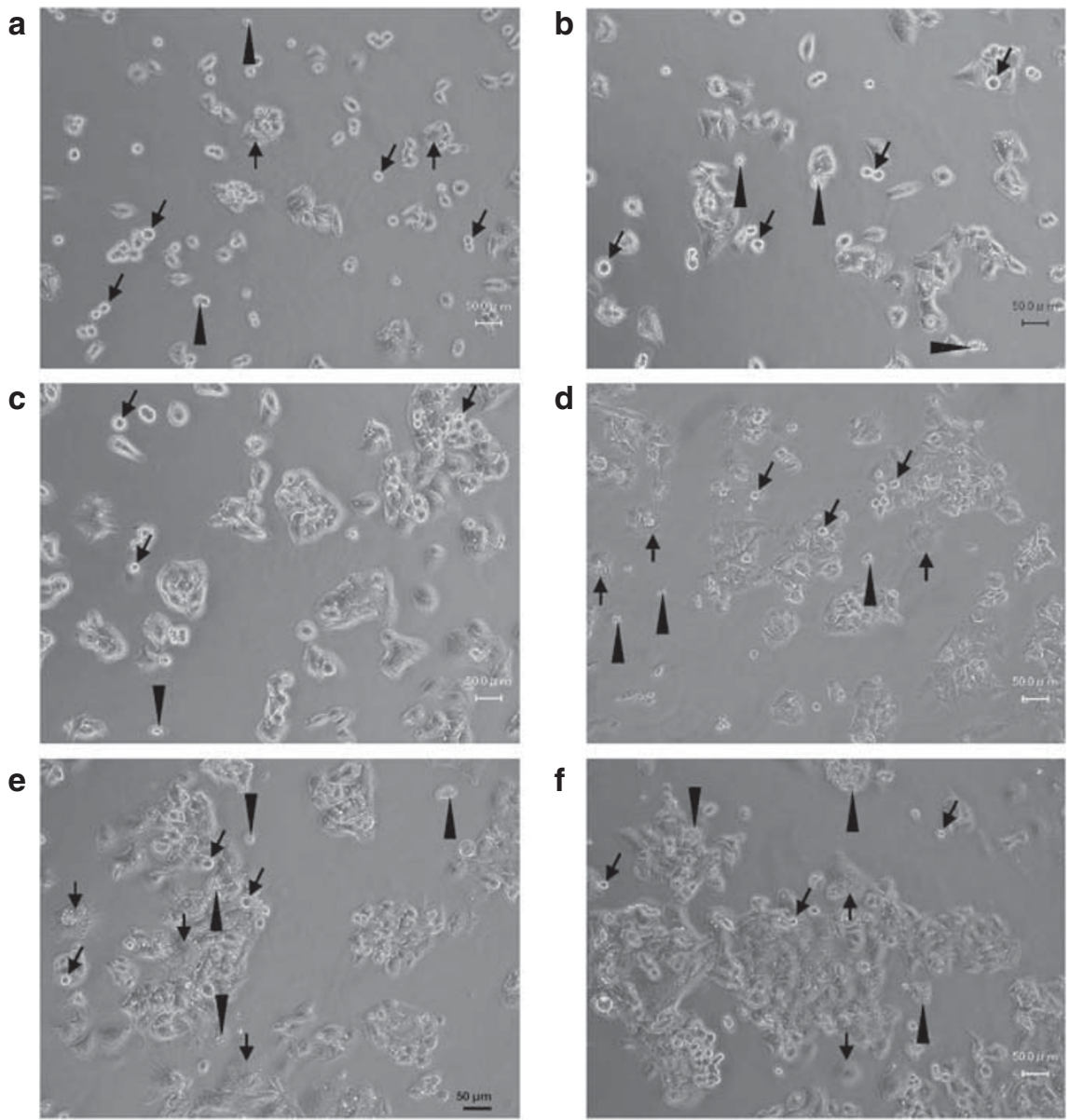

Figure 2 Microscopic appearance of radioresistant HepG2-8960-R cells after acute exposure to 10 Gy of X-rays. (a) HepG2-8960-R cells 2 days after exposure to 2 Gy of X-rays (maintenance irradiation). Mitotic cells (black arrows), dead cells (black arrow heads) and multinucleated cells showing mitotic catastrophe (white arrows) were observed. (b) No remarkable changes were observed 1 day after exposure to 10 Gy of X-rays. (c) Unlike HepG2 cells the increase in cell size was not obvious 2 days after exposure to 10 Gy of X-rays. (d) Mitotic figures were not apparent compared with HepG2 cells 3 days after exposure to 10 Gy of X-rays. (e) At day 5 after exposure to 10 Gy of $X$-rays, the frequency of dead cells was lower compared with HepG2. (f) At day 7 after exposure to 10 Gy of $X$-rays, the number of cells in mitotic catastrophe was not increased

Basal levels of dead cells were higher in radioresistant HepG2-8960-R than HepG2 (Figure 2a), presumably due to maintenance irradiation at 2 Gy per day. During this experimental period, distinguishable induction of cell death was not observed (Figures 2a-f). At day 3 after AR, inconsiderable increase in non-apoptotic cell death was observed in HepG28960-R (Figure 2d). After that no increase in either dead cells or mitotic catastrophe was observed (Figures $2 e$ and f). These suggested that apoptosis is not a major type of cell death induced by ionizing radiation.

To examine to what extent X-ray exposure induces apoptotic changes, apoptotic cell death was evaluated by different methods. Basal level of annexin V-positive apoptotic cells observed under a microscope was significantly higher in HepG2-8960-R than in HepG2 (Figure 3a). AR of 10 Gy increased the frequency of annexin $V$-positive cells both in HepG2 and HepG2-8960-R. The increase was faster and higher in HepG2-8960-R than that in HepG2. The maximum level was about $20 \%$ in HepG2-8960-R and $10 \%$ in HepG2. The frequency of annexin V-positive cells was constant in both cell lines after reaching the maximal level. On the other hand, fractionated radiation (FR) of $2 \mathrm{~Gy}$ per day did not induce significant frequency of annexin V-positive cells both in HepG2 and HepG2-8960-R (Figure 3b). We next examined DNA ladder formation, a hallmark of apoptosis. Although 5 days after AR, many dead cells were observed in the cell culture (Figure 1e), DNA ladder formation was not observed in both HepG2 and HepG2-8960-R at any time examined (Supplementary Figure S1A). Radiation-induced DNA ladder formation was not detectable in SAS and SAS-R (Supplementary Figure S1B). We further examined the expression of cleaved caspase 3 after irradiation. After AR, significant increase in cleaved caspase 3 was not detectable by western blotting from 0 to 7 days after AR in all cell lines examined (data not shown). Radiosensitivity under the inhibition of apoptosis by Z-VAD-FMK was evaluated. The inhibition of apoptosis sensitized both HepG2 and HepG2-8960-R to $\mathrm{X}$-rays slightly at lower doses and significantly at $10 \mathrm{~Gy}$ (Supplementary Figures S2A and B). However, the inhibition of apoptosis did not affect surviving fractions of SAS and 


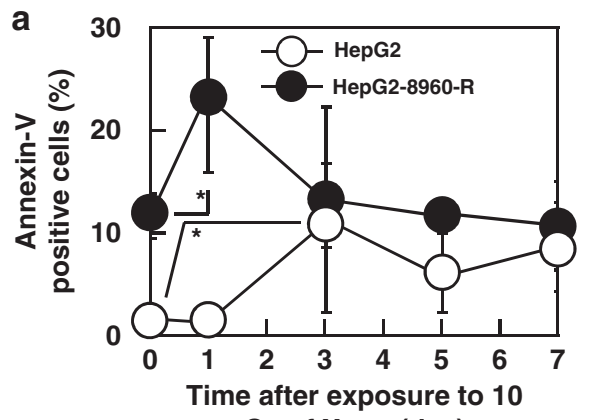

Gy of X-ray (day)

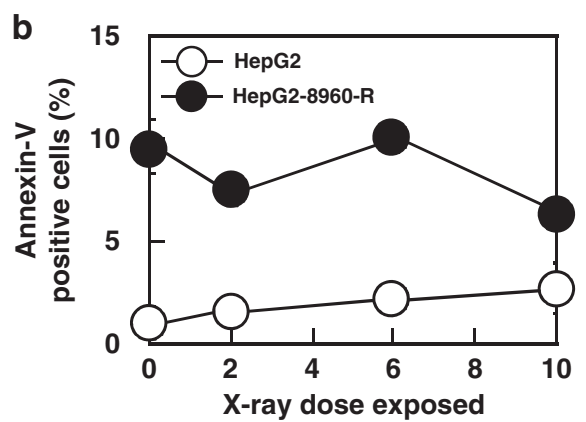

(2 Gy/day)

Figure 3 Frequencies of annexin V-positive cells induced by 10 Gy of a single dose of X-rays or fractionated X-rays. Basal levels of annexin V-positive cells in radioresistant HepG2-8960-R were higher than those in parental HepG2. (a) Annexin V-positive cells in HepG2 and HepG2-8960-R increased after acute exposure, however, induction level of annexin V-positive cells in HepG2 was higher than that in HepG2-8960-R. (b) Statistically significant induction of apoptosis was not observed both in HepG2 and HepG2-8960-R after exposure to fractionated $2 \mathrm{~Gy}$ of X-rays. Mean \pm S.D. of three independent experiments. ${ }^{*} P<0.05$ compared with control

SAS-R (Supplementary Figures S2C and D). These results indicated that contribution of apoptosis to cellular radiosensitivity is lower than previously considered.

Autophagy induced by X-ray exposure. We analyzed immunocytochemically positive cells for LC-3, a marker of autophagosomes. AR induced cells whose cytoplasm was filled with autophagosomes both in HepG2 and HepG2-8960-R (Figure 4). We defined these characteristic cells as 'hyperinduced autophagic cells' (Figures $4 \mathrm{~b}$ and $\mathrm{c}$ ). The frequency of hyperinduced autophagic cells in HepG2-8960-R $(24.0 \pm 5.2 \%)$ was significantly higher than that in HepG2 $(1.5 \pm 0.7 \%)$. Within $24 \mathrm{~h}$ after AR of $10 \mathrm{~Gy}$, hyperinduced autophagic cells did not increase in both HepG2 and HepG28960-R (Supplementary Figure S3). Electron microscopic observation also confirmed that autophagic cell death was induced both in HepG2 and HepG2-8960-R by AR (Figures $4 \mathrm{e}-\mathrm{h}$ ). The frequency of hyperinduced autophagic cells in HepG2 gradually increased from day 3 and reached $78.2 \pm 6.1 \%$ at day 7 after AR (Figure 5a). On the contrary, marked induction of hyperinduced autophagic cells was not observed in HepG2-8960-R and the frequency was $40.9 \pm 8.6 \%$ at day 7 . Exposure to $5 \times 2$ Gy of FR remarkably induced hyperinduced autophagic cells in HepG2 (45.9 $\pm 6.9 \%)$ but not in HepG2-8960-R (24.2 $\pm 1.8 \%$; Figure $5 b)$. We next examined the conversion of LC3-I to LC3-II, which is an indicator of autophagic activity and the amount of LC3-II correlates well with the number of autophagosomes. ${ }^{22}$ At day 5 after AR, LC3-II level increased in both HepG2 and HepG28960-R, and the induction level was higher in HepG2 than in HepG2-8960-R (Figure 5c). We further examined the expression level of p62, which accumulates when autophagy is inhibited and decreases when autophagy is induced. ${ }^{23}$ Without irradiation the expression level of p62 in HepG2 was higher than that in HepG2-8960-R (Figure 5d). The expression of p62 in HepG2 remained reduced from day 3 to 7 after AR and that in HepG2-8960-R reduced at day 3 but returned to the basal level by day 7 .

Radiosensitization of CRR cells via induction of autophagy. Radiosensitivity after facilitation of autophagy by RPM was evaluated. Chronic exposure to radiation reduces plating efficiency on which reproducibility of clonogenic assay depends. Therefore, in this study the modified high-density survival (HDS) assay instead of clonogenic assay was used to determine cellular radiosensitivity. HepG2-8960-R and all other CRR cell lines examined were significantly radioresistant compared with their corresponding parental cell lines (Figure 6a, Supplementary Figure S4). Radiosensitivity of HepG28960-R with RPM treatment became almost the same as that of HepG2 (Figure 6b). RPM also sensitized both HepG2$R$ and SAS-R (Supplementary Figures S4B and D) and its radiosensitizing effect tended to be higher at higher doses. Radiosensitivity of HepG2 with or without RPM was not significantly different (Supplementary Figure S5A). The inhibition of autophagy by 3-methyladenine (3-MA) did not radiosensitize HepG2-8960-R (Supplementary Figure S5D), but made HepG2 radioresistant to the level of HepG2-8960-R and even more resistant than HepG2-R (Figure 6C and Supplementary Figure S6B). Radioresistance was also induced in SAS by 3-MA (Supplementary Figure S6D). However, these effects were not observed in both HepG2-R and SAS-R (Supplementary Figures S6B and D).

Autophagy induced by FR. RPM at the concentration of $10 \mathrm{ng} / \mathrm{ml}$ for 5 days was not toxic to HepG2 (Figure 7a), but significantly suppressed cell growth of HepG2-8960-R at day 5 (Figure $7 \mathrm{~b}$ ). FR alone suppressed cell growth of HepG2 (Supplementary Figure S7A), but additional radiosensitizing effect of RPM was not detected (Figure 7c). On the other hand, cell growth of HepG2-8960$R$ was drastically suppressed by the administration of $F R$ and RPM (Figure 7d) and this effect was reinforced by FR (Supplementary Figure S7D).

Cell growth of HepG2 was suppressed by 3-MA (Figure 7e). The effect of 3-MA on the cell growth was not obvious in HepG2-8960-R (Figure 7f). Radiosensitizing effect of 3-MA on FR was not observed both in HepG2 (Figure $7 \mathrm{~g}$, Supplementary Figure S7E) and in HepG2-8960-R (Figure 7h, Supplementary Figure S7F).

Radiosensitizing effect of RPM was also confirmed in HepG2-R and SAS-R cells but not in SAS cells, indicating that the CRR phenotype is reversed by RPM (Supplementary 
a

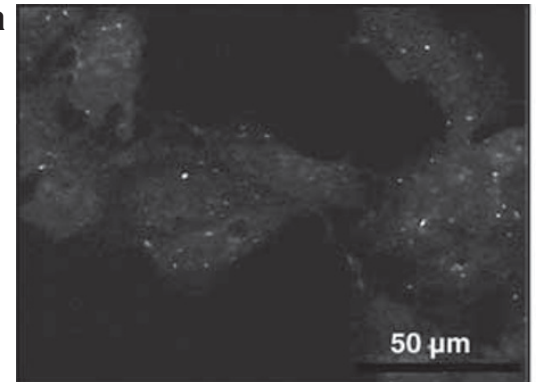

C

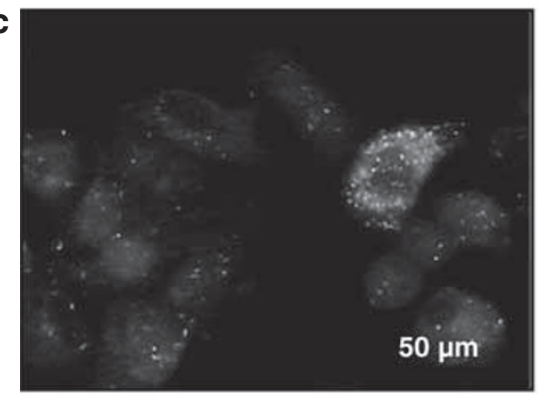

e

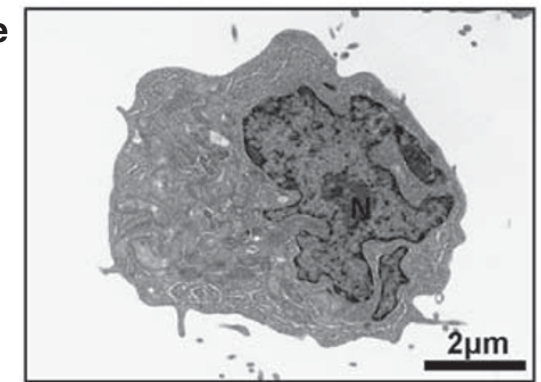

9

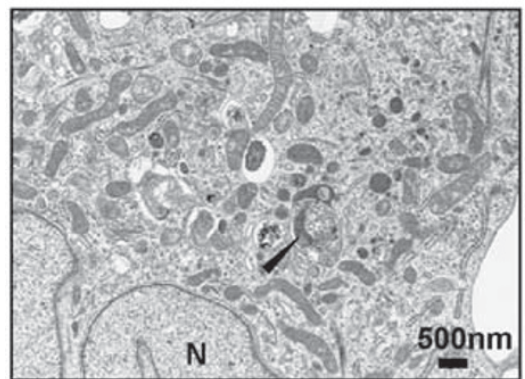

b

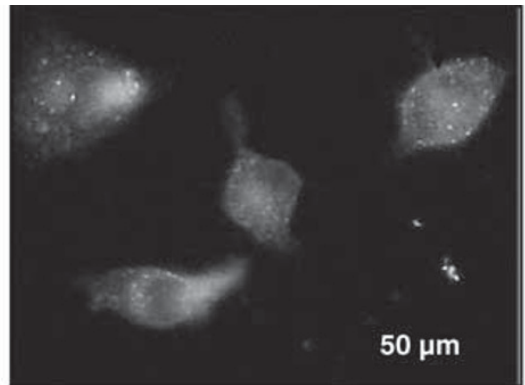

d

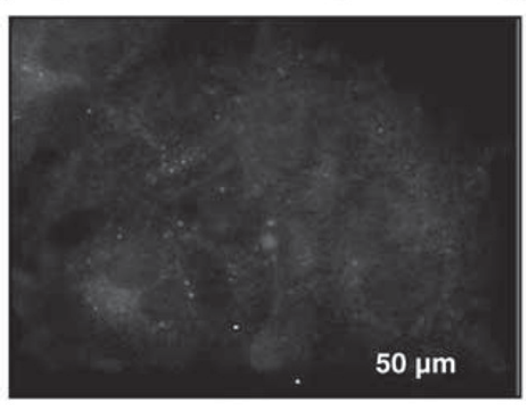

$\mathbf{f}$

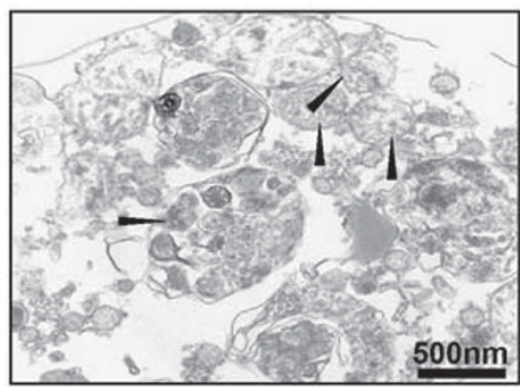

$\mathbf{h}$

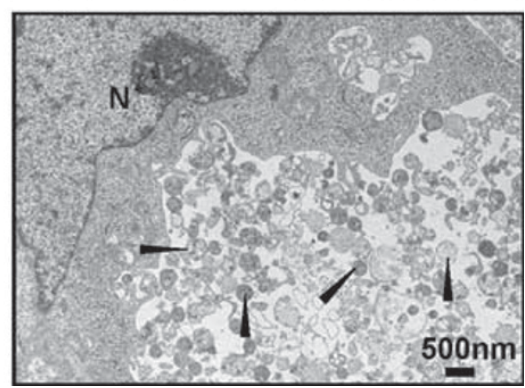

Figure 4 (a-d) Representative figures of hyperinduced autophagic cells by a single dose of 10-Gy X-rays in parental HepG2 and radioresistant HepG2-8960-R cells. Autophagosomes were immunocytochemically visualized by anti-LC-3 antibody and cells filled with autophagosomes were counted as hyperinduced autophagic cells (arrows). (e-h) Electron microscopic analysis of HepG2 and HepG2-8960-R. (a) Hyperinduced autophagic cells were seldom observed in HepG2 cells without irradiation. (b) At day 7 after exposure to $10 \mathrm{~Gy}$ of X-rays, the level of hyperinduced autophagic HepG2 cells was $78.2 \pm 6.1 \%$. (c) HepG2-8960-R cells 2 days after the last maintenance irradiation (2 Gy per day). (d) At day 7 after exposure to 10 Gy of X-rays, significant induction of hyperinduced autophagic cells was not observed in HepG2-8960-R. (e) HepG2 cells without X-rays. (f) At day 5 after exposure to $10 \mathrm{~Gy}$ of X-rays, HepG2 cells were filled with autophagosomes (arrow head). (g) HepG2-8960-R cell 2 days after the last maintenance irradiation (2 Gy per day). (h) HepG2-8960-R cell filled with autophagosomes at day 5 after exposure to 10 Gy of X-rays

Figures S8B, D and F). On the other hand, administration of 3-MA conferred radioresistance on SAS against FR (Supplementary Figure S8D).

We next examined whether administration of RPM or 3-MA induces apoptosis, mitotic catastrophe or hyperinduced autophagic cells. At day 5 after irradiation, the frequency of annexin V-positive cells was not significantly different between with or without RPM or 3-MA (Supplementary Figure S9A). The induction frequency of mitotic catastrophe was not different between HepG2 and HepG2-8960-R irrespective of
RPM or 3-MA treatments (Supplementary Figure S9B). Although RPM increased the frequency of hyperinduced autophagic cells in HepG2-8960-R 7 days after AR, unexpectedly did not in HepG2. Administration of 3-MA suppressed $X$-ray-induced hyperinduced autophagic cells in HepG2 (Supplementary Figure 9C).

Beclin-1 knockdown and radiosensitivity. We further examined whether inhibition of autophagy by knockdown of Beclin-1 induces radioresistance or not. We used psiRNA- 


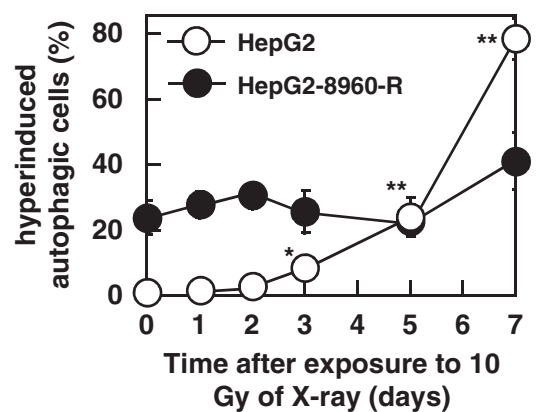

b

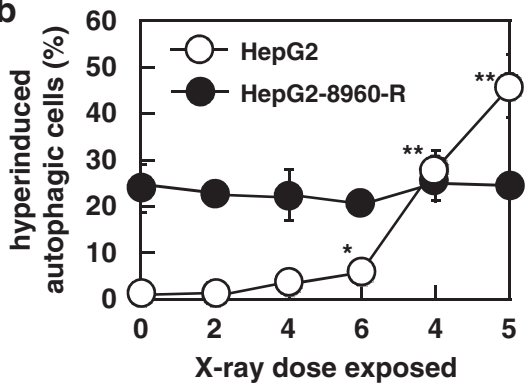

(2 Gy/Day)

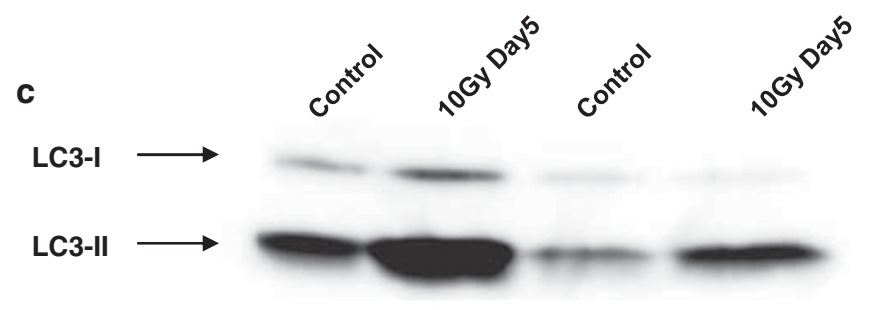

actin

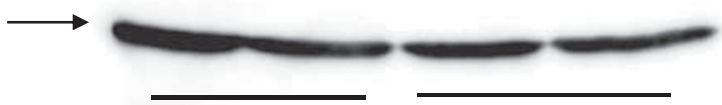

HepG2

HepG2-8960-R

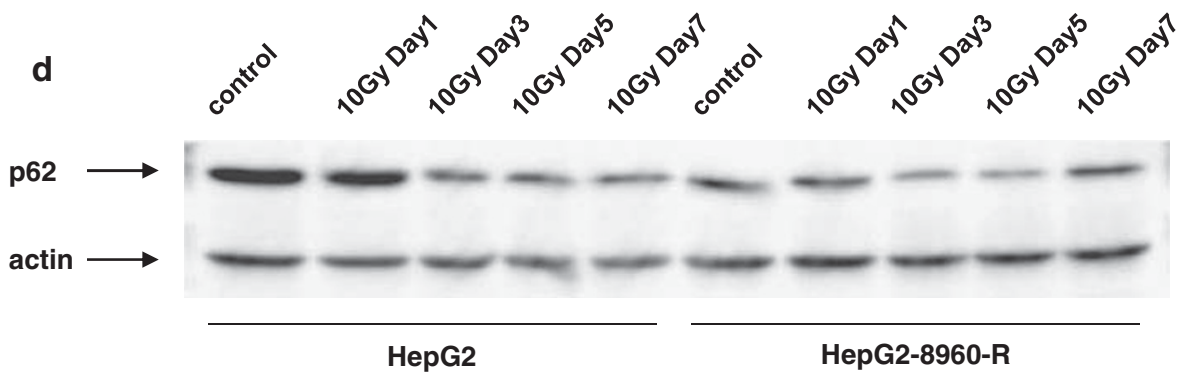

Figure 5 (a) Hyperinduced autophagic cells by 10 Gy of X-rays in parental HepG2 and radioresistant HepG2-8960-R cells. The induction level of hyperinduced autophagic cells in HepG2-8960-R was lower than that in HepG2. (b) Hyperinduced autophagic cells by fractionated 2 Gy of X-rays. Hyperinduced autophagic cells of HepG2 were gradually increased along with the dose. No increase in hyperinduced autophagic cells was observed in HepG2-8960-R after exposure to total 10 Gy of X-rays. Mean \pm S.D. of three independent experiments. ${ }^{\star \star} P<0.01,{ }^{*} P<0.05$ compared with control. (c) Western blot analysis of LC3 protein after X-irradiation. At day 5 after exposure to 10 Gy of $X$-rays, the increase in LC3-II, a hallmark of the induction of autophagy, was observed in both parental HepG2 and radioresistant HepG2-8960-R, and the amount of LC3-II in HepG2 was higher than that in HepG2-8960-R. (d) Western blot analysis of p62 protein after X-irradiation. At day 5 after exposure to 10 Gy of X-rays, the reduction of p62 protein, a hallmark of the induction of autophagy, was observed in both parental HepG2 and radioresistant HepG2-8960-R, and the amount of p62 protein in HepG2 was reduced much more than that in HepG2-8960-R
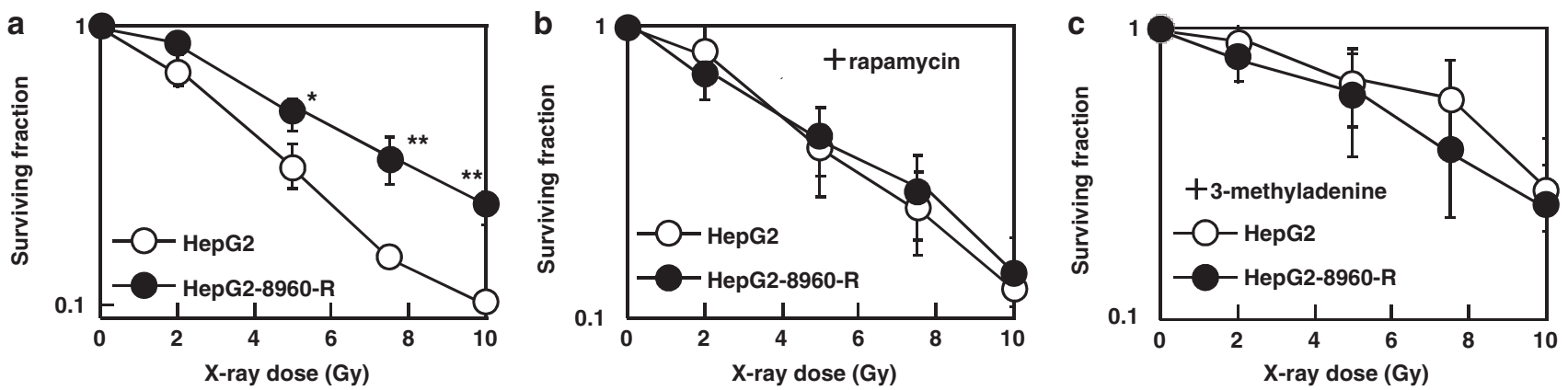

Figure 6 (a) HepG2-8960-R was significantly more radioresistant than HepG2 at all doses examined. (b) The effect of RPM on radiosensitivity of HepG2 and HepG28960-R. RPM canceled radioresistance of HepG2-8960-R to the levels of HepG2. (c) The effect of 3-MA on radiosensitivity of HepG2 and HepG2-8960-R. HepG2 cells acquired the radioresistant phenotype by the administration of 3-MA. Mean \pm S.D. of three independent experiments was calculated. ${ }^{\star} P<0.05$, ${ }^{\star \star} P<0.01$ 
a

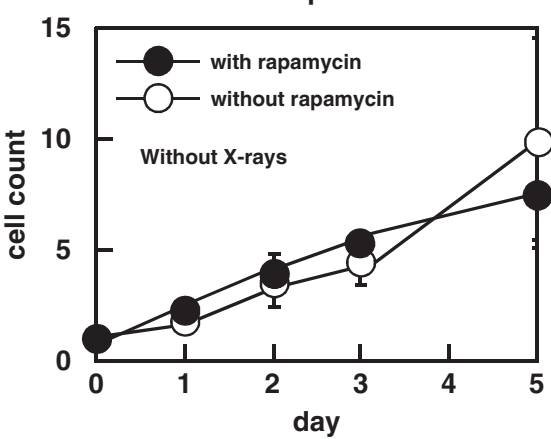

C
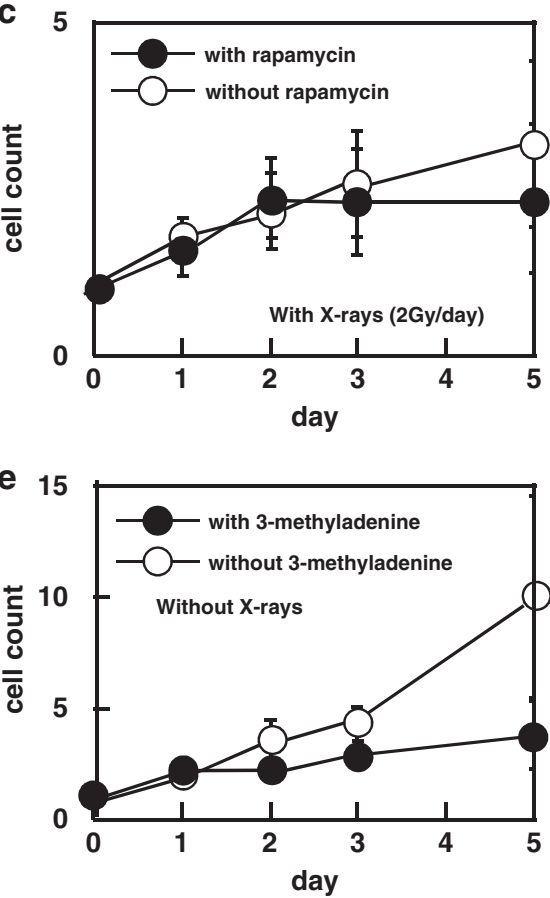

g

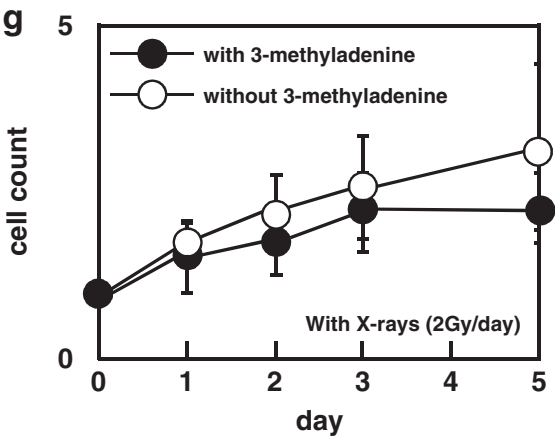

b

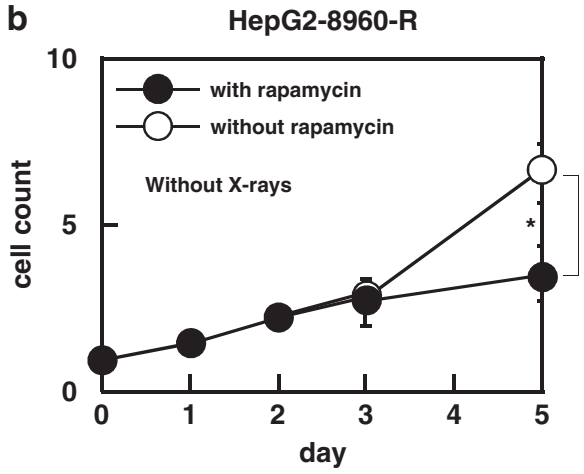

d 5
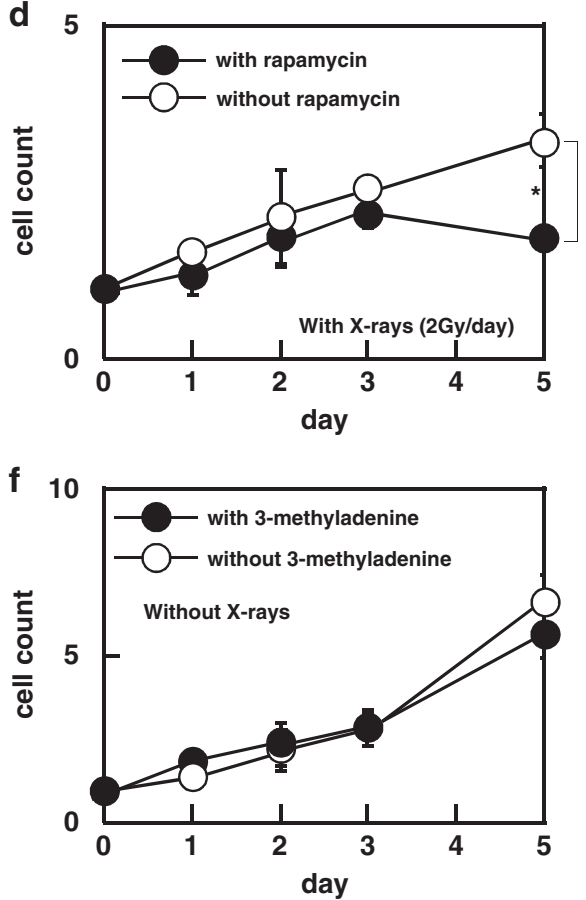

hith 3-methyladenine

Figure 7 (a-d) Combined effect of FR of 2 Gy of X-rays (FR) and RPM on cell growth. (a) RPM (10 ng/ml) did not affect cell growth of HepG2. (b) RPM significantly suppressed cell growth of HepG2-8960-R without radiation. (c) Until cumulative dose of 10 Gy, RPM did not affect cell growth of HepG2. (d) Cell growth of HepG2-8960-R was significantly suppressed by the administration of RPM with cumulative $10 \mathrm{~Gy}$ of X-rays. (e-h) Combined effect of fractionated 2 Gy of X-rays and administration of 3-MA on cell growth. (e) Cell growth of HepG2 was suppressed by the administration of 3-MA, but no significance was detected at any point examined. (f) Administration of 3-MA had no effect on cell growth of HepG2-8960-R cells. (g) Cell growth of HepG2 with fractionated 2 Gy of X-rays was not significantly different between with and without 3-MA. (h) Cell growth of HepG2-8960-R with fractionated 2 Gy of X-rays was not different between with and without 3-MA. Mean \pm S.D. of three independent experiments were calculated. ${ }^{*} P<0.01$

hBeclin-1 for knockdown and siRNA-Luc for control of transfection. HepG2 gradually died out during selection for psiRNA-hBeclin-1 transfectant for three independent experiments. Without irradiation, autophagosomes were not observed both in siRNA-Luc SAS and psiRNA-hBeclin-1 SAS (Figure 8a). Five days after exposure to 10-Gy AR, 
a

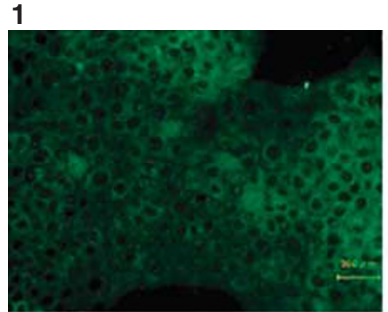

4

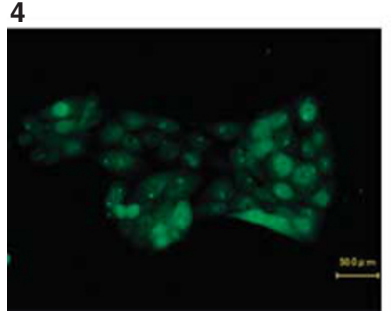

b

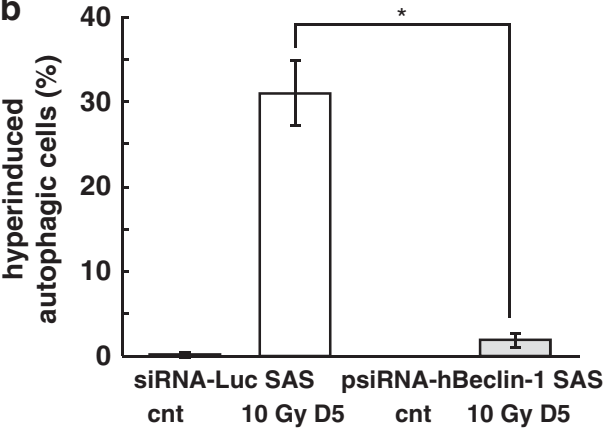

2

5
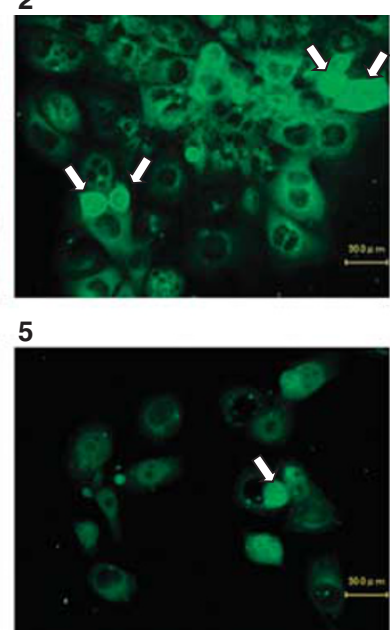

C

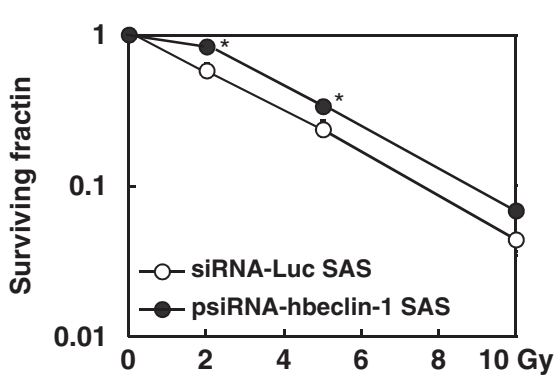

3

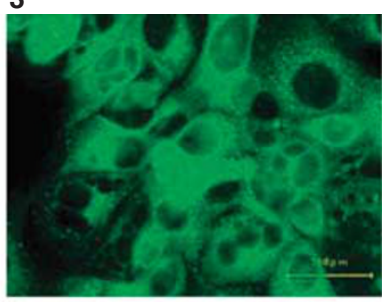

6

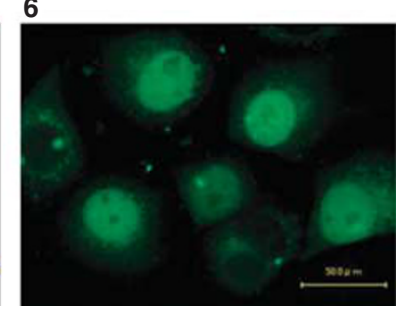

.

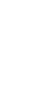

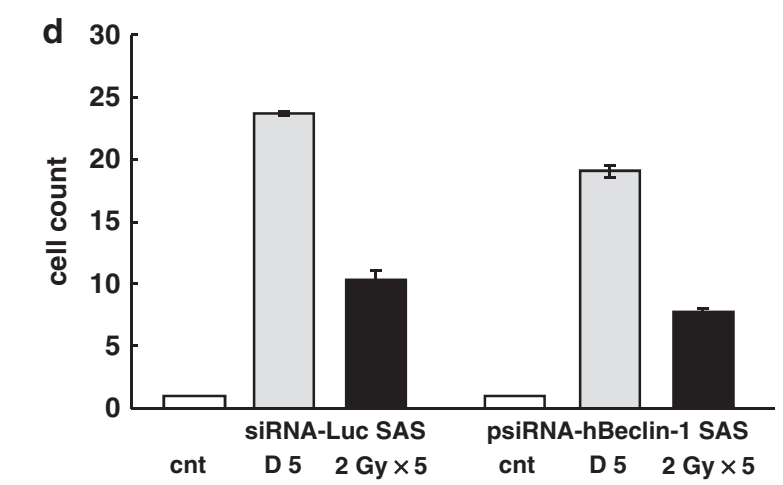

Figure 8 (a) Representative figures of autophagic cells induced by a single dose of 10-Gy X-rays in siRNA-Luc SAS and psiRNA-hBeclin-1 SAS cells. Autophagosomes were immunocytochemically visualized by anti-LC-3 antibody. (a-1) siRNA-Luc SAS cells without irradiation. (a-2) siRNA-Luc SAS cells 5 days after exposure to 10 Gy. In almost all cells the number of autophagosomes were increased. Some cells entered into hyperinduced autophagic cells (arrows). (a-3) siRNA-Luc SAS cells 5 days after exposure to 10 Gy of X-rays. High magnification. (a-4) psiRNA-hBeclin-1 SAS cells without irradiation. These cells express GFP as a marker for transfection. Therefore faint fluorescence was observed in nuclei. (a-5) psiRNA-hBeclin-1 SAS cells 5 days after exposure to 10 Gy of X-rays. Although autophagosomes were observed in cytoplasm, the number was apparently lower than that of siRNA-Luc SAS cells, indicating that induction of autophagy is suppressed by Beclin-1 knockdown. (a-6) psiRNA-hBeclin-1 SAS cells 5 days after exposure to 10 Gy of X-rays. High magnification. (b) Hyperinduced autophagic cells 5 days after exposure to 10 Gy of X-rays in siRNA-Luc SAS and psiRNAhBeclin-1 SAS cells. (c) Radiation sensitivity of siRNA-Luc SAS and psiRNA-hBeclin-1 SAS. (d) Cell growth of siRNA-Luc SAS and psiRNA-hBeclin-1 SAS without radiation or $5 \times 2$ Gy of $X$-rays. Mean \pm S.D. of three independent experiments. ${ }^{*} P<0.05$

increases of the nuclear size and autophagosomes were observed in siRNA-Luc SAS. On the other hand, notable increase in autophagosomes was not observed in psiRNAhBeclin-1 SAS. These results indicated that induction of autophagy by AR is suppressed in psiRNA-hBeclin-1 SAS. Compared with siRNA-Luc SAS, induction of hyperinduced autophagic cells 5 days after exposure to $A R$ was significantly suppressed in psiRNA-hBeclin-1 SAS (Figure 8b). We next examined whether inhibition of autophagy induces cellular radioresistance or not. Compared with siRNA-Luc SAS radioresistance of psiRNAhBeclin-1 SAS was observed (Figure 8c). Growth rate of psiRNA-hBeclin-1 SAS was slightly slower than that of siRNA-Luc SAS (Figure 8d). Compared with un-irradiated 
cells, FR of $5 \times 2$-Gy suppressed cell growth of both siRNALuc SAS and psiRNA-hBeclin-1 SAS but the suppression level was not significantly different. These results indicated that autophagy is a determinant factor of cellular radiosensitivity at least after AR of X-rays.

\section{Discussion}

Although radiotherapy is a well-established modality for various cancers, appearance of radioresistant cells is one of the major concerns. In order to understand and conquer radioresistant tumors, we have established CRR cell lines. ${ }^{20,21}$ Profile of radiation-induced cell death under a microscope could be divided into two major types: cell death with apoptotic bodies and that lacking apoptotic bodies. We speculated that the latter was autophagic cell death. This study revealed that apoptotic changes were observed but the induction level of apoptosis was very low both in parental and CRR cells. Moreover, the inhibition of apoptosis by a caspase inhibitor, Z-VAD-FMK, did not always radiosensitize both CRR and their parental cells. These suggest that contribution of apoptosis to cellular radiosensitivity is not remarkable. One of the hallmarks of cancer cells is thought to evade apoptosis. ${ }^{24,25}$ However, apoptosis has little or no effect on clonogenic survival after treatment with anticancer drugs or radiation in several tumor cell lines. ${ }^{2}$ Recently, mounting evidences suggest that cancer cells can commit to death by various non-apoptotic pathways such as autophagy, ${ }^{26}$ mitotic catastrophe and accelerated senescence. ${ }^{4}$ In this study, maximum level of mitotic catastrophe within a week after AR was approximately $10 \%$ of HepG2 cells. This observation prompted us to examine the contribution of autophagic cell death to cellular radiosensitivity.

Autophagic cell death known as type II programmed cell death is independent of phagocytes and differs from apoptosis by the presence of autophagosomes, autolysosomes and an intact nucleus in the cell. ${ }^{27}$ In this study, electron microscopic study revealed that radiation exposureinduced characteristic morphology to autophagic cell death. Recently, autophagy is widely investigated in the field of radiation oncology. ${ }^{28}$ However, the role of autophagy for cellular radiosensitivity remains to be elucidated. In this study, induction of autophagy by radiation was time dependent, which is consistent with Paglin et al. ${ }^{15}$ But they reported that the induction of autophagy protects cells from radiation. In this study, microscopic observation of LC3 immunocytochemistry revealed cells characterized by their cytoplasm filled with autophagosomes other than cells with a few autophagosomes. As the frequency of this distinctive type of cells increased after AR, we coined them 'hyperinduced autophagic cells'. The frequency of hyperinduced autophagic cells in parental cells increased after AR and was significantly higher than in CRR cells 7 days after AR. Western blot analysis of LC3II revealed that the number of autophagosomes both at the basal level and the induced level after AR were lower in CRR cells than in parental cells. Western blotting of p62 revealed that the autophagy function at the basal level was higher in CRR cells than in parental cells. Both the number and the function of autophagosomes were increased by AR in parental cells while not obvious in CRR cells. These suggest that hyperinduced autophagy is associated with radiation-induced cell death albeit basal level of autophagy may contribute to the protection of cells.

RPM induces autophagy and combination with radiation facilitates the development of autophagy in human mammary carcinoma MCF-7 cells accompanied with reduction of cell survival. $^{29}$ In this study, radiosensitizing effect of RPM on parental cells was not observed, presumably because we used RPM at the concentration of $1 / 10$ of the usually reported to avoid its toxic effects. We confirmed that this dose was enough to induce autophagy after exposure to $10 \mathrm{~Gy}$ in CRR cells. The HDS assay with RPM showed that lower dose of RPM than usual was enough to reverse radioresistance of CRR cells to the levels of their corresponding parental cells. Therefore, treatments with low dose RPM would be useful to sensitize radioresistant tumors. Inhibition of autophagy by 3-MA did not change radiosensitivity of CRR cells, but increased radioresistance in parental cells to the levels of corresponding CRR cells after exposure to AR. Inhibition of autophagy by knockdown of Beclin-1 in SAS cells also induced radioresistance against $A R$. Lin et al. ${ }^{30}$ reported that the inhibition of autophagy promotes resistance of papillary thyroid cancer (PTC) to radiation and the activation of autophagy may be a useful adjunct treatment for patients with PTC that is refractory to conventional therapy. In this study, 3-MA did not make parental cells radioresistant to FR. The frequency of hyperinduced autophagic cells in HepG2 was $80 \%$ at day 7 after exposure to 10 Gy of AR whereas $45 \%$ after exposure to $5 \times 2$ Gy of FR. Compared with AR the lower levels of induced autophagy by FR may partly contribute to the reason why the inhibition of autophagy either by 3-MA or Beclin-1 knockdown had lower impact on the cellular radioresistance of parental cells. In this study, we failed in obtaining Beclin-1 knockdown HepG2. This suggests that the basal level of autophagy is inevitable for cell survival though the level required is cell line dependent. Basal level of autophagy is necessary for cell survival against cellular stresses. ${ }^{31}$ In this study, the function of autophagy at the basal level for cell protection is suggested to be higher in CRR cells than in parental cells. Radioresistance can be acquired through moderate dose of FR for 1 month. ${ }^{20}$ These suggest that factor(s) to determine whether autophagy is involved in cell survival or cell death is different between CRR cells and parental cells.

This study also strongly suggested that the activation of autophagy may overcome tumor radioresistance. Those are consistent with reports that the activation of autophagy may yield significant benefit for cancer patients undergoing radiotherapy. ${ }^{32-34}$ Radioresistant tumors could be surmountable by radiotherapy in combination with autophagy inducers such as RPM and RAD001 (everolimus). ${ }^{35}$

Radiation-induced cell death in HepG2 began to increase 4 days after AR with the increase in mitotic catastrophe. Mitotic catastrophe is a well-established response to ionizing radiation. ${ }^{36}$ Mitotic catastrophe occurs either during or shortly after a dysregulated/failed mitosis and is thought to be the process to cell death. ${ }^{37}$ In this study, mitotic figures started increasing 3 days after AR, suggesting that cells failed to progress mitosis go into cell death. We presented here that about $80 \%$ of HepG2 cells after exposure to AR underwent 
autophagic cell death. Roughly $1 / 3$ of cells in mitotic catastrophe were filled with autophagosomes, suggesting that these cells would die through autophagic cell death. Therefore, we think the majority of radiation-induced cell death is autophagic cell death.

This study revealed that induction of autophagy sensitized CRR cells both to AR and FR. Therefore, we conclude that the modality to induce autophagy can be one of the effective approaches to conquer radioresistant tumors. ${ }^{38}$ We started experiments on xenografted tumors of CRR cells into nude mice to evaluate whether the inhibition of mTOR pathway is effective to eradicate radioresistant tumors or not.

\section{Materials and Methods}

Cell culture and chemicals. HepG2 cells derived from human liver cancer and SAS cells from human oral cancer were obtained from the Cell Resource Center for Biomedical Research, Institute of Development, Aging and Cancer, Tohoku University. We established CRR cell lines, HepG2-8960-R and HepG2-R from HepG2, and SAS-R from SAS independently. For the maintenance of the CRR phenotype, FR of X-rays at 2 Gy was performed every $24 \mathrm{~h}$. All cells used in this study were maintained in Roswell Park Memorial Institute (RPMI) 1640 medium (Nacalai Tesque Inc., Kyoto, Japan) supplemented with $5 \%$ fetal bovine serum (Gibco Invitrogen Corp., Carlsbad, CA, USA) in a humidified atmosphere at $37^{\circ} \mathrm{C}$ with $5 \% \mathrm{CO}_{2}$ in an air. In this study, acute exposure experiments were performed with cells in the exponentially growing phase and $24 \mathrm{~h}$ after the last maintenance irradiation.

As an inhibitor of apoptosis, Z-VAD-FMK $(20 \mu \mathrm{M})$ was used (Promega KK, Tokyo, Japan). For the induction of autophagy, RPM (Nacalai Tesque Inc.) dissolved in ethanol $(1 \mathrm{mg} / \mathrm{ml})$ was used at the final concentration of $10 \mathrm{ng} / \mathrm{ml} .{ }^{39} \mathrm{As}$ an inhibitor of autophagy, 3-MA (Sigma-Aldrich Inc., St. Louis, MO, USA) was used at the concentration of $1 \mathrm{mM}$ by directly dissolved in culture medium before use. ${ }^{40}$ These agents were administered in cell culture $24 \mathrm{~h}$ before experiments.

Irradiation. X-ray irradiation was performed in a $150-\mathrm{KVp}$ X-ray generator (Model MBR-1520R, Hitachi, Tokyo, Japan) with a total filtration of $0.5 \mathrm{~mm}$ aluminum plus $0.1 \mathrm{~mm}$ copper filter at a dose rate of $1.0 \mathrm{~Gy} / \mathrm{min}$. In this study, we performed two different modes of irradiation, FR and AR. Exposure schedule of FR consisted of $2 \mathrm{~Gy}$ of X-rays every $24 \mathrm{~h}$ up to 5 days (total $10 \mathrm{~Gy}$ ) and AR consisted of exposure to a single dose of $10-G y$ X-rays.

Detection of apoptotic cells. To determine the percentage of cells undergoing apoptosis, FITC annexin V/Dead Cell Apoptosis Kit (Molecular Probes, Eugene, OR, USA) was used according to the manufacture's protocol. Briefly, after exposure to X-rays, cells were washed with PBS and stained with annexin V. Immediately after staining, annexin $\mathrm{V}$-positive cells were scored under a fluorescent microscope.

Detection of mitotic catastrophe. After exposure to X-rays, cells were fixed with methyl alcohol and stained with giemsa solution. Cells with more than two nucleus and micronuclei were considered as mitotic catastrophe.

Immunocytochemical detection of autophagy. Cells were seeded on a cover slip $48 \mathrm{~h}$ before radiation exposure experiments. At an appropriate time after irradiation, cells were rinsed twice with phosphate-buffered saline (PBS) and then fixed with $4 \%$ paraformaldehyde in PBS for 10 min at room temperature (RT). Cells were washed twice more with PBS and immersed in $100 \mu \mathrm{g} / \mathrm{ml}$ of Digitonin (Wako Pure Chemical Industries, Ltd., Osaka, Japan) in PBS for 15 min at RT. After two more washings with PBS, anti-LC3 primary antibody (Medical and Biological Laboratories Co., Ltd., Nagoya, Japan) was applied. After 1-h incubation at RT, cells were washed three times with PBS (5 min each). Cells were then incubated with fluorescein-conjugated second antibody (Santa Cruz Biotechnology, Inc., Santa Cruz, CA, USA) in PBS for 30 min at RT. Then, cells were washed three times with PBS (5 min each) and Vectorshield (Vector Laboratories, Inc., Burlingame, CA, USA) was mounted onto the cover slips. Autophagosomes were visualized in a fluorescence microscope (BZ-8000, Keyence, Osaka, Japan).
The HDS assay. Cell survival was determined by the modified HDS assay. ${ }^{21}$ Briefly, exponentially growing cells were seeded in $25 \mathrm{~cm}^{2}$ flasks at $1 \times 10^{5}$ per flask for parental cells and $2.5 \times 10^{5}$ per flask for CRR cells. After 24 -h incubation, cells were exposed to various doses of X-rays and incubated for another $72 \mathrm{~h}$. Subsequently, $1 / 10$ of the cells of each flask were seeded into another $25 \mathrm{~cm}^{2}$ flask and incubated for further $72 \mathrm{~h}$. Then total number of cells in each flask was counted by Trypan blue dye exclusion test and cell survival was plotted.

Western blot analysis. To prepare whole cell lysate, cells were washed twice with ice-cold PBS and resuspended in a lysis buffer containing $25 \mathrm{mM}$ sodium phosphate (pH7.4), $500 \mathrm{mM} \mathrm{NaCl}, 1 \mathrm{mM}$ ethylenediaminetetraacetic acid (pH 8.0), $0.5 \%$ Triton-X100, $0.1 \%$ glycerol, $5 \mathrm{mM} \mathrm{MgCl}, 1 \mathrm{mM}$ dithiothreitol, $1 \mathrm{mM}$ phenylmethylsulfonyl fluoride and Protease Inhibitor Cocktail (Nacalai Tesque Inc.). Cells were centrifuged for $20 \mathrm{~min}$ at $4^{\circ} \mathrm{C}$ and clarified supernatants were stored at $-80^{\circ} \mathrm{C}$ until use. The whole cell lysate $(20 \mu \mathrm{g})$ was electrophoresed in sodium dodecyl sulfate polyacrylamide gel and was electroblotted onto a polyvinylidene fluoride membrane. After blocking with $5 \%$ skim milk for overnight at $4{ }^{\circ} \mathrm{C}$, the membrane was incubated for overnight with primary antibodies at $4{ }^{\circ} \mathrm{C}$ and then incubated with horseradish peroxidase-conjugated secondary antibodies (Nichirei Corporation, Tokyo, Japan). Anti-cleaved caspase-3 antibody and anti-LC3 antibody were purchased from Cell Signaling Technology Japan, KK (Tokyo, Japan) and anti-p62/SQSTM1 antibody from MBL Co., Ltd., Nagaya, Japan). Bands were visualized with Chemi-Lumi One $L$ western blotting substrate (Nacalai Tesque Inc.).

DNA fragmentation assay. After harvesting cells including detached cells were washed twice with ice-cold PBS and genomic DNA was extracted using DNeasy Blood and Tissue Kit (Qiagen K K, Tokyo, Japan).

Cell survival after exposure to fractionated $2 \mathrm{~Gy}$ of X-rays. Cells $\left(1 \times 10^{5}\right)$ were seeded into a $25-\mathrm{cm}^{2}$ flask (Nalge Nunc International, Rochester, $\mathrm{NY}$, USA) $48 \mathrm{~h}$ before the first experimental irradiation, and $24 \mathrm{~h}$ later RPM or 3-MA was administered. These cells were daily exposed to $2 \mathrm{~Gy}$ of X-rays for 5 consecutive days without medium exchange. At the appropriate time point during this experiment, total number of cells was scored and relative value of control was calculated.

Electron microscopy. HepG2 cells grown in 60-mm culture dishes were washed twice with PBS. Cells were fixed in $100 \mathrm{mM}$ phosphate buffer, $\mathrm{pH} 7.4$, containing $2.5 \%$ glutaraldehyde for $30 \mathrm{~min}$ at $4{ }^{\circ} \mathrm{C}$. The cells were rinsed twice with ice-cold PBS, post-fixed in $\mathrm{OsO}_{4}$, dehydrated in graded acetone and embedded in epoxy resin. Ultrathin sections were prepared with Ultra-microtome (Leica Microsystems Japan, Tokyo, Japan), mounted in copper grids, and counterstained with uranyl acetate and lead citrate. Photographs were obtained using transmission electron microscope (Hitachi High-Technologies Corporation, Tokyo, Japan).

Inhibition of autophagy by Beclin-1 knockdown. In order to inhibit autophagy, a psiRNA-hBeclin-1 Kit was used according to the manufacture's protocol (InvivoGen, San Diego, CA, USA). Briefly, cells were transfected with expression vector using HilyMax (Dojindo, Kumamoto, Japan). These cells were cultured in RPMI medium containing $5 \%$ fetal bovine serum and Zeocin $(100 \mu \mathrm{g} / \mathrm{ml}$, InvivoGen) for 2 weeks. The viable cell preparation was used for experiments.

Statistical analysis. At each data point, the mean and S.D. were calculated and statistically analyzed using Student's $t$-test.

\section{Conflict of Interest}

The authors declare no conflict of interest.

Acknowledgements. We thank Biomedical Research Core of Tohoku University Graduate School of Medicine for technical support. This study was in part supported by the Grant-in-Aid for young scientists from Ministry of Education, Culture, Sports, Science and Technology, by a grant from RADIATION EFFECT ASSOCIATION and by a grant from the Ministry of Health, Labour and Welfare of Japan. 
1. Schmitt CA, Fridman JS, Yang M, Lee S, Baranov E, Hoffman RM et al. A senescence program controlled by $\mathrm{p} 53$ and $\mathrm{p} 16 \mathrm{INK} 4 \mathrm{a}$ contributes to the outcome of cancer therapy. Cell 2002; 109: 335-346.

2. Roninson IB, Broude EV, Chang BD. If not apoptosis, then what? Treatment-induced senescence and mitotic catastrophe in tumor cells. Drug Resist Updat 2001; 4: 303-313.

3. Kondo $\mathrm{Y}$, Kanzawa $\mathrm{T}$, Sawaya R, Kondo S. The role of autophagy in cancer development and response to therapy. Nat Rev Cancer 2005; 5: 726-734.

4. Gewirtz DA, Holt SE, Grant S. Apoptosis, Senescence and Cancer, 2nd edn. Humana Press: Totowa, NJ, USA, 2007.

5. Endlich B, Radford IR, Forrester HB, Dewey WC. Computerized video time-lapse microscopy studies of ionizing radiation-induced rapid-interphase and mitosis-related apoptosis in lymphoid cells. Radiat Res 2000; 153: 36-48.

6. Kim R, Emi M, Tanabe K, Uchida Y, Arihiro K. The role of apoptotic or nonapoptotic cell death in determining cellular response to anticancer treatment. Eur J Surg Oncol 2006; 32 269-277.

7. Finkel E. Does cancer therapy trigger cell suicide? Science 1999; 286: 2256-2258.

8. Brown JM, Wouters BG. Apoptosis, p53, and tumor cell sensitivity to anticancer agents. Cancer Res 1999; 59: 1391-1399.

9. Brown JM, Wilson G. Apoptosis genes and resistance to cancer therapy: what does the experimental and clinical data tell us? Cancer Biol Ther 2003; 2: 477-490.

10. Ogier-Denis E, Codogno P. Autophagy: a barrier or an adaptive response to cancer. Biochim Biophys Acta 2003; 1603: 113-128.

11. Gozuacik D, Kimchi A. Autophagy as a cell death and tumor suppressor mechanism Oncogene 2004; 23: 2891-2906.

12. Cuervo AM. Autophagy: in sickness and in health. Trends Cell Biol 2004; 14: 70-77.

13. Bursch W, Ellinger A, Kienzl H, Torok L, Pandey S, Sikorska M et al. Active cell death induced by the anti-estrogens tamoxifen and $\mathrm{ICl} 164384$ in human mammary carcinoma cells (MCF-7) in culture: the role of autophagy. Carcinogenesis 1996; 17: 1595-1607.

14. Bauvy C, Gane P, Arico S, Codogno P, Ogier-Denis E. Autophagy delays sulindac sulfideinduced apoptosis in the human intestinal colon cancer cell line HT-29. Exp Cell Res 2001; 268: 139-149.

15. Paglin S, Hollister T, Delohery T, Hackett N, McMahill M, Sphicas E et al. A novel response of cancer cells to radiation involves autophagy and formation of acidic vesicles. Cancer Res 2001; 61: 439-444.

16. Jia L, Dourmashkin RR, Allen PD, Gray AB, Newland AC, Kelsey SM. Inhibition of autophagy abrogates tumour necrosis factor alpha induced apoptosis in human T-lymphoblastic leukaemic cells. Br J Haematol 1997; 98: 673-685.

17. Shintani T, Klionsky DJ. Autophagy in health and disease: a double-edged sword. Science 2004; 306: 990-995.

18. Yao KC, Komata T, Kondo Y, Kanzawa T, Kondo S, Germano IM. Molecular response of human glioblastoma multiforme cells to ionizing radiation: cell cycle arrest, modulation of the expression of cyclin-dependent kinase inhibitors, and autophagy. J Neurosurg 2003; 98: 378-384.

19. Apel A, Zentgraf $\mathrm{H}$, Buchler MW, Herr I. Autophagy-A double-edged sword in oncology. Int J Cancer 2009; 125: 991-995.

20. Kuwahara Y, Li L, Baba T, Nakagawa H, Shimura T, Yamamoto $Y$ et al. Clinically relevant radioresistant cells efficiently repair DNA double-strand breaks induced by X-rays. Cancer Sci 2009; 100: 747-752.

21. Kuwahara Y, Mori M, Oikawa T, Shimura T, Ohtake Y, Mori S et al. The modified highdensity survival assay is the useful tool to predict the effectiveness of fractionated radiation exposure. J Radiat Res 2010; 51: 297-302.
22. Kabeya $\mathrm{Y}$, Mizushima N, Ueno T, Yamamoto A, Kirisako T, Noda T et al. LC3, a mammalian homologue of yeast Apg8p, is localized in autophagosome membranes after processing. EMBO J 2000; 19: 5720-5728.

23. Bjorkoy G, Lamark T, Pankiv S, Overvatn A, Brech A, Johansen T. Monitoring autophagic degradation of p62/SQSTM1. Methods Enzymol 2009; 452: 181-197.

24. Hanahan D, Weinberg RA. The hallmarks of cancer. Cell 2000; 100: 57-70.

25. Lefranc F, Facchini V, Kiss R. Proautophagic drugs: a novel means to combat apoptosisresistant cancers, with a special emphasis on glioblastomas. Oncologist 2007; 12: 1395-1403.

26. Fujiwara $K$, Iwado $E$, Mills GB, Sawaya R, Kondo S, Kondo $Y$. Akt inhibitor shows anticancer and radiosensitizing effects in malignant glioma cells by inducing autophagy. Int J Oncol 2007; 31: 753-760.

27. Reggiori F, Klionsky DJ. Autophagosomes: biogenesis from scratch? Curr Opin Cell Biol 2005; 17: 415-422.

28. Zois CE, Koukourakis Ml. Radiation-induced autophagy in normal and cancer cells: towards novel cytoprotection and radio-sensitization policies? Autophagy 2009; 5: 442-450.

29. Paglin S, Lee NY, Nakar C, Fitzgerald M, Plotkin J, Deuel B et al. Rapamycin-sensitive pathway regulates mitochondrial membrane potential, autophagy, and survival in irradiated MCF-7 cells. Cancer Res 2005; 65: 11061-11070.

30. Lin $\mathrm{Cl}$, Whang EE, Abramson MA, Jiang X, Price BD, Donner DB et al. Autophagy: a new target for advanced papillary thyroid cancer therapy. Surgery 2009; 146: 1208-1214.

31. Mizushima N, Levine B, Cuervo AM, Klionsky DJ. Autophagy fights disease through cellular self-digestion. Nature 2008; 451: 1069-1075.

32. Dalby KN, Tekedereli I, Lopez-Berestein G, Ozpolat B. Targeting the prodeath and prosurvival functions of autophagy as novel therapeutic strategies in cancer. Autophagy 2010; 6: 322-329.

33. Turcotte S, Giaccia AJ. Targeting cancer cells through autophagy for anticancer therapy. Curr Opin Cell Biol 2010; 22: 246-251.

34. Moretti L, Yang ES, Kim KW, Lu B. Autophagy signaling in cancer and its potential as nove target to improve anticancer therapy. Drug Resist Updat 2007; 10: 135-143.

35. Lin Cl, Whang EE, Donner DB, Du J, Lorch J, He F et al. Autophagy induction with RAD001 enhances chemosensitivity and radiosensitivity through Met inhibition in papillary thyroid cancer. Mol Cancer Res 2010; 8: 1217-1226.

36. Vakifahmetoglu H, Olsson M, Zhivotovsky B. Death through a tragedy: mitotic catastrophe. Cell Death Differ 2008; 15: 1153-1162.

37. Kroemer G, Galluzzi L, Vandenabeele P, Abrams J, Alnemri ES, Baehrecke EH et al. Classification of cell death: recommendations of the Nomenclature Committee on Cell Death 2009. Cell Death Differ 2009; 16: 3-11.

38. Ciuffreda L, Di Sanza C, Incani UC, Milella M. The mTOR pathway: a new target in cancer therapy. Curr Cancer Drug Targets 2010; 10: 484-495.

39. Rubinsztein DC, Gestwicki JE, Murphy LO, Klionsky DJ. Potential therapeutic applications of autophagy. Nat Rev Drug Discov 2007; 6: 304-312.

40. Kanzawa T, Germano IM, Komata T, Ito H, Kondo Y, Kondo S. Role of autophagy in temozolomide-induced cytotoxicity for malignant glioma cells. Cell Death Differ 2004; 11: 448-457.

Cell Death and Disease is an open-access journal published by Nature Publishing Group. This work is licensed under the Creative Commons Attribution-Noncommercial-Share Alike 3.0 Unported License. To view a copy of this license, visit http:// creativecommons.org/licenses/by-nc-sa/3.0/

Supplementary Information accompanies the paper on Cell Death and Disease website (http://www.nature.com/cddis) 